\title{
PRACTICE PARAMETER: EARLY DETECTION OF DEMENTIA: MILD COGNITIVE IMPAIRMENT (AN EVIDENCE-BASED REVIEW)
}

\author{
Report of the Quality Standards Subcommittee of the American Academy of Neurology \\ R.C. Petersen, PhD, MD; J.C. Stevens, MD; M. Ganguli, MD, MPH;,E.G. Tangalos, MD; \\ J.L. Cummings, MD; and S.T. DeKosky, MD
}

\begin{abstract}
Article abstract-Objective: The goal of this project was to determine whether screening different groups of elderly individuals in a general or specialty practice would be beneficial in detecting dementia. Background: Epidemiologic studies of aging and dementia have demonstrated that the use of research criteria for the classification of dementia has yielded three groups of subjects: those who are demented, those who are not demented, and a third group of individuals who cannot be classified as normal or demented but who are cognitively (usually memory) impaired. Methods: The authors conducted computerized literature searches and generated a set of abstracts based on text and index words selected to reflect the key issues to be addressed. Articles were abstracted to determine whether there were sufficient data to recommend the screening of asymptomatic individuals. Other research studies were evaluated to determine whether there was value in identifying individuals who were memory-impaired beyond what one would expect for age but who were not demented. Finally, screening instruments and evaluation techniques for the identification of cognitive impairment were reviewed. Results: There were insufficient data to make any recommendations regarding cognitive screening of asymptomatic individuals. Persons with memory impairment who were not demented were characterized in the literature as having mild cognitive impairment. These subjects were at increased risk for developing dementia or AD when compared with similarly aged individuals in the general population. Recommendations: There were sufficient data to recommend the evaluation and clinical monitoring of persons with mild cognitive impairment due to their increased risk for developing dementia (Guideline). Screening instruments, e.g., Mini-Mental State Examination, were found to be useful to the clinician for assessing the degree of cognitive impairment (Guideline), as were neuropsychologic batteries (Guideline), brief focused cognitive instruments (Option), and certain structured informant interviews (Option). Increasing attention is being paid to persons with mild cognitive impairment for whom treatment options are being evaluated that may alter the rate of progression to dementia.
\end{abstract}

NEUROLOGY 2001;56:1133-1142

Introduction. Mission statement. The Quality Standards Subcommittee (QSS) seeks to develop scientifically sound, clinically relevant practice parameters for the practice of neurology. When the previous practice parameter, Diagnosis and Evaluation of Dementia, was published in 1994 the issue of early detection was not addressed. ${ }^{1}$ Since then, considerable progress has been made in identifying more mildly impaired subjects who may be in a transitional stage between normal aging and dementia.

Initially, the members of the detection work group phrased the following clinical question: Does screening of subjects with a specific instrument in a specific setting accurately lead to the diagnosis of dementia? After an extensive literature review, the work group concluded that there were insufficient data in the literature to allow an evidence-based approach to the question of the clinical utility of screening asymptomatic individuals for dementia. Epidemiologic studies

The appointment of authors for this guideline was done in cooperation with the Alzheimer's Association and overlaps significantly with the membership of the Medical and Scientific Advisory Council and the Board of Directors of the association. The Alzheimer's Association agrees with the content of this paper in all important regards.

This guideline has been endorsed by the American Association of Neuroscience Nurses and the American Geriatrics Society.

From the Department of Neurology (Dr. Petersen), Mayo Clinic, Rochester, MN; Lutheran Medical Office (Dr. Stevens), Fort Wayne, IN; Department of Psychiatry, University of Pittsburgh School of Medicine and Department of Epidemiology, University of Pittsburgh Graduate School of Public Health (Dr. Ganguli), Pittsburgh, PA; Department of Internal Medicine (Dr. Tangalos), Mayo Clinic, Rochester, MN; Departments of Neurology and Psychiatry \& Biobehavioral Science (Dr. Cummings), University of California at Los Angeles; Departments of Neurology and Psychiatry (Dr. DeKosky), University of Pittsburgh, PA.

Approved by the AAN Quality Standards Subcommittee November 11, 2000. Approved by the AAN Practice Committee January 6, 2001. Approved by the AAN Board of Directors February 24, 2001.

Received July 21, 2000. Accepted in final form February 13, 2001.

Address correspondence and reprint requests to the Quality Standards Subcommittee, American Academy of Neurology, 1080 Montreal Ave., St. Paul, MN 55116.

Copyright (C) 2001 by AAN Enterprises, Inc. 
of aging and dementia have demonstrated that the use of research criteria for the classification of dementia identifies three groups of subjects: those who are demented, those who are not demented, and individuals who cannot be classified because they have a cognitive (memory) impairment but do not meet criteria for dementia. The work group then turned its attention to an evaluation of this group of subjects.

In the recent literature, attention has been paid to the transitional stage of cognitive impairment between normal aging and early $\mathrm{AD}$, so-called mild cognitive impairment. ${ }^{2}$ Mild cognitive impairment refers to the clinical state of individuals who are memory impaired but are otherwise functioning well and do not meet clinical criteria for dementia (table 1). Several multicenter treatment trials are under way to determine whether
Table 1 Mild cognitive impairment criteria

Memory complaint, preferably corroborated by an informant Objective memory impairment Normal general cognitive function Intact activities of daily living Not demented

Table 2 Classification of evidence

\begin{tabular}{lc}
\hline Class & Description \\
\hline I & Evidence provided by one or more well designed, \\
& randomized, controlled clinical trials, including \\
& overviews (meta-analyses) of such trials \\
II & Evidence provided by well designed observational \\
& studies with concurrent controls (e.g., case control \\
& or cohort studies) \\
III & Evidence provided by expert opinion, case series, case \\
& reports, and studies with historical controls
\end{tabular}
various therapeutic measures can alter the rate at which these subjects progress to AD. Collectively, these studies emphasize the need for the clinician to detect the earliest signs of cognitive impairment. This practice parameter was modified to determine whether screening at-risk subjects (by virtue of memory impairment) with a specific instrument in a specific setting leads to the diagnosis of dementia.

The impact of these questions is significant. As of 1990, there were 4 million individuals in the United States with AD. ${ }^{3}$ This number is expected to increase to 14 million by $2050 .^{4}$ In 1998 , the annual cost for the care of patients with AD in the United States was approximately $\$ 40,000$ per patient. If one were able to successfully treat mild cognitive impairment such that the progression of these individuals to AD could be delayed by one year, there would be significant savings.

Clinical question statement. The work group then simplified the questions as follows: 1) Does the presence of mild cognitive impairment predict the development of dementia?2) Does screening at-risk subjects with a specific instrument in a specific setting lead to the diagnosis of dementia? To put this literature in perspective, the work group reviewed the incidence data available for dementia and $\mathrm{AD}$ in the age group represented by the studies on mild cognitive impairment to provide a frame of reference for the mild cognitive impairment to AD conversion rates. Various instruments used in the detection of dementia were also analyzed for their sensitivity, specificity, and positive and negative predictive values.

Process. Panel selection. The QSS identified two team leaders to select committee members to participate in the creation of one or more practice parameters on dementia. The committee determined that three practice parameters were needed: Detection of Dementia, Diagnosis of Dementia, and Management of Dementia. The three practice parameter committees coordinated their literature searches to include key words such as specific forms of dementia and databases that interrelate the three topics. All panel members provided comprehensive disclosures of any real or potential conflicts of interest.

Literature review process. Search terms. Key and index words used were as follows: dementia, presenile dementia, senile dementia, vascular dementia, AD, early detection, early diagnosis, early stages, early symptoms, health screening, psychologic screening inventory, geriatric assessment, longitudinal studies, retrospective studies, mild cognitive impairment, Mini-Mental State Examination, cognitive impairment, cognitive assessment, and memory tests.

Data bases. MEDLINE, EMBASE, Current Contents, Psychological Abstracts, Psych Info, Cochrane Database, and CINAHL Database were searched.

Inclusion/exclusion criteria and process. For the searches we sought studies in all languages; however, other types of studies were limited to English only. Studies were restricted to human subjects. Longitudinal prospective studies that evaluated mildly impaired subjects and followed them to detect cognitive impairment from 1991 to early 2000 were reviewed. We also examined reviews and their bibliographies published from 1994 to November 1999 to identify additional articles. In addition, we evaluated studies of clinical testing instruments that could be used to identify subjects with cognitive impairment.

Number and disposition of articles. We identified 1,933 abstracts, which yielded 120 articles. Application of appropriate inclusion/exclusion criteria yielded 74 articles that provided the evidence for this parameter.

Data extraction items. Articles were reviewed by at least two individuals and selected items were coded onto a data extraction form that had the following information: type of article, focus of article (e.g., diagnosis of dementia, early dementia), number of subjects, sex, subject selection method, method of patient characterization, screening instruments used, final diagnostic classification, gold standard for final diagnostic classification, quality of diagnostic methods, formal diagnostic criteria used, diagnostic criteria for AD (if applicable), age of population studied (if study dealt with test or instrument), name and value, sensitivity, specificity, positive predictive value, negative predictive value, and final classification of evidence. 
Classification of evidence. Each article was assigned to a class of evidence based on a priori definitions (table 2). The class of evidence determined whether or not study results were ultimately translated into Standards, Guidelines, or Options (table 3).

Development of evidence tables. For all articles, evidence tables were developed. These tables indicate the author and year of the study, level of evidence, main purpose of the study, population, intervention, outcome measure, and result.

Table 3 Levels of recommendation

\begin{tabular}{ll}
\hline Recommendation & \multicolumn{1}{c}{ Level of evidence } \\
\hline Standard & $\begin{array}{c}\text { Principle for patient management that reflects a } \\
\text { high degree of clinical certainty. (Usually } \\
\text { requires Class I evidence that directly addresses } \\
\text { clinical questions, or overwhelming Class II } \\
\text { evidence when circumstances preclude } \\
\text { randomized clinical trials.) } \\
\text { Recommendation for patient management that } \\
\text { reflects moderate clinical certainty. (Usually } \\
\text { requires Class II evidence or a strong consensus } \\
\text { of Class III evidence.) } \\
\text { Strategy for patient management for which clinical } \\
\text { utility is uncertain (inconclusive or conflicting } \\
\text { evidence or opinion). }\end{array}$ \\
\hline
\end{tabular}

Analysis of evidence. Does the presence of mild cognitive impairment predict the development of dementia? The work group assessed longitudinal studies of persons with mild cognitive impairment to determine whether classification of such persons leads to an increased risk of developing AD relative to the general age-matched population. Overall ("crude") estimates are less than adequate for comparison among studies because study cohorts may vary in their age structures. Even when using age-specific or age-adjusted incidence rates, varying diagnostic/inclusion criteria affect comparability of studies. For example, some studies include persons with incipient dementia, others include mild dementia, and still others only included individuals with moderate to severe dementia. ${ }^{5}$ As an example of the effect of such difference, two studies of largely white cohorts in the northeastern United States generated widely disparate incidence rates. The age-specific annual incidence rates for AD in the group aged 60 to 65 was $0.6 \%$ per year in the East Boston study. ${ }^{7}$ This study included mild cases and did not require functional impairment for the definition of dementia. In contrast, in the Framingham study only individuals with moderate to severe dementia were included and the incidence was $0.07 \%$ per year, ${ }^{8}$ one-tenth of the rate reported from East Boston. However, in both the Framingham and the East Boston studies the incidence rates for the group aged $85+$ were 14 times higher than in the 65 to 69 age group. ${ }^{7,8}$

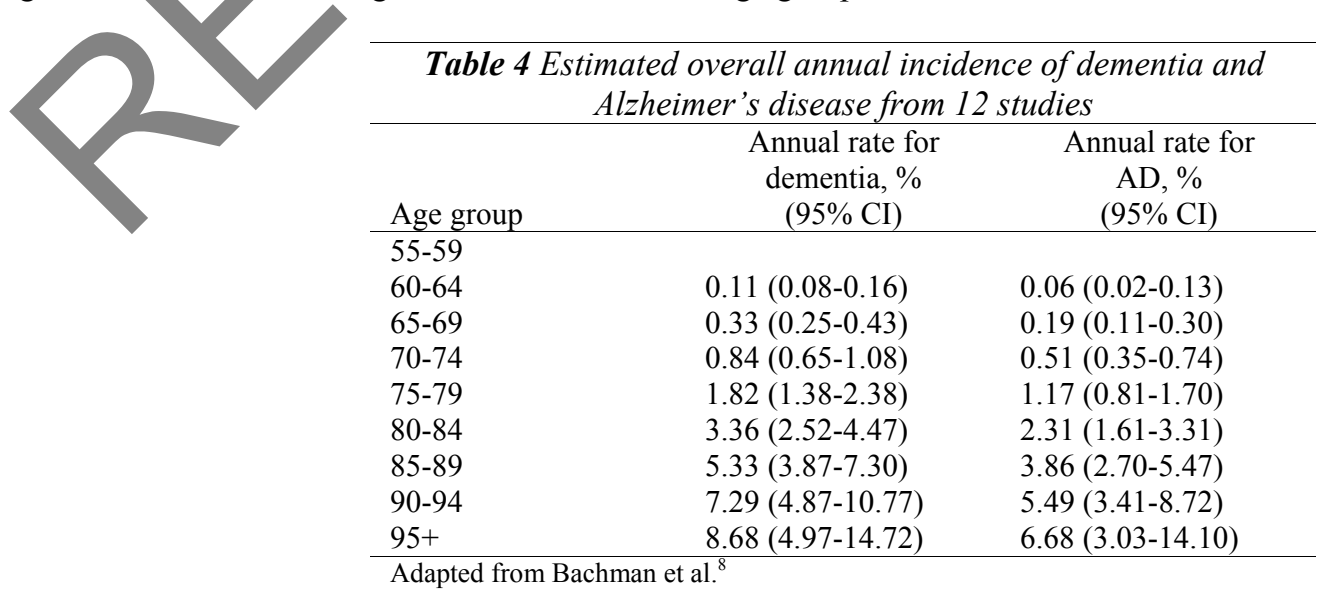

Table 4 gives estimated, annual age-specific incidence rates for all dementias and for AD averaged in a meta-analysis of 12 studies by Gao et al. ${ }^{9}$ The average incidence rate for AD across studies for ages 70 to 74 years is $0.51 \%$, increasing to $3.9 \%$ at ages 85 to 89 .

With these incidence estimates as a frame of reference, we compared rates of conversion to dementia for persons classified as having mild cognitive impairment. Mild cognitive impairment refers to the state of cognition and functional ability between normal aging and very mild AD. Various terms have been used to describe this stage, including mild cognitive impairment, isolated memory impairment, incipient dementia, and dementia prodrome, but all these terms refer to a similar constellation of findings. ${ }^{10}$ In other literature, terms such as age-associated memory impairment (AAMI) and 
Table 5 Studies demonstrating outcome of persons with mild cognitive impairment (MCI) or similar condition

\begin{tabular}{|c|c|c|c|c|c|c|c|}
\hline Study & $\begin{array}{l}\text { Subjects, } \\
\text { no. }\end{array}$ & $\begin{array}{c}\text { Mean age, } \\
y\end{array}$ & Source & Criteria & $\begin{array}{c}\text { Duration } \\
\text { follow- } \\
\text { up, y }\end{array}$ & $\begin{array}{c}\text { Annual } \\
\text { conversion } \\
\text { rate to } \\
\text { dementia or } \\
\text { AD, } \%\end{array}$ & Class \\
\hline Mayo $^{2}$ & 66 & 81 & Community practice & MCI & 4 & 12 & II \\
\hline Toronto $^{14,15}$ & 107 & 74 & Family practice & Memory impairment & 2 & 14 & II \\
\hline Columbia $^{16}$ & 127 & 66 & Memory disorders clinic & Questionable dementia & 2.7 & 15 & II \\
\hline $\mathrm{MGH}^{17}$ & 123 & 72 & Community advertising & CDR 0.5 & 3 & 6 & II \\
\hline Seattle ${ }^{18}$ & 21 & 74 & $\begin{array}{l}\text { Health Maintenance } \\
\text { Organization }\end{array}$ & Isolated memory loss & 3.8 & 12 & III \\
\hline NYU $^{19}$ & 32 & 71 & Dementia clinic & GDS 3 & 2.2 & 25 & III \\
\hline
\end{tabular}

$\mathrm{CDR}=$ Clinical Dementia Rating; GDS = Global Deterioration Scale.

age-associated cognitive decline (AACD) have been used. They are distinct from the concept of mild cognitive

impairment as used in the current article. Age-associated memory impairment refers to the concept of increasing memory impairment with age and references memory function in the elderly cohort to young normal adult subjects. As such, there can be an overinclusion of neurologically normal individuals in this concept, and it has been critiqued as such. ${ }^{13}$ Ageassociated cognitive decline refers to the concept of mild impairments in multiple cognitive domains but not of sufficient severity to constitute the diagnosis of dementia. This is a useful concept; however, few longitudinal studies have been conducted using this nomenclature, and this classification scheme also includes many normal elderly persons. Each of these terms either includes a segment of the normal population and represents extremes of normal aging and/or is more inclusive than the current definition of mild cognitive impairment. As such, they are not directly germane to the current discussion. Individuals with mild cognitive impairment meet criteria similar to those shown in table 1 . There are differences in the literature with respect to the sources of subjects, age, education, and criteria, but a general pattern of clinical progression has emerged. These studies are summarized in table 5. The conversion criteria refer to either the development of dementia or AD.

In a Class II U.S. study from the Mayo Clinic's longitudinal study of aging and dementia, subjects were recruited from a primary care practice which served the residents of Rochester, MN. ${ }^{2}$ Subjects were enrolled if they expressed a concern about their cognitive function, a family member appreciated a change in cognitive function, or the primary care physician indicated a concern. These were community-dwelling individuals, and the mean age at the time of enrollment was 81 years. The subjects were classified as haying mild cognitive impairment if they met criteria similar to those shown in table 1 . When the subjects were followed for up to 4 years, they converted to AD at a rate of $12 \%$ per year. ${ }^{2}$ By 6 years approximately $80 \%$ of the individuals had developed AD. ${ }^{10}$

In another Class II Canadian study from a similar setting in Toronto, 107 subjects with a memory impairment without dementia were followed for 2 years. ${ }^{14,15}$ Subjects were referred to the study by family physicians, and the mean age of the subjects was 74 years. During the 2-year follow-up, 29 (approximately 28\%) developed AD for an approximate annual conversion rate of $14 \%$.

A Class II U.S. study exploring the natural history of subjects from a memory disorders clinic at Columbia University evaluated 127 consecutive subjects with "questionable dementia." However, these subjects did not meet criteria for dementia. ${ }^{16}$ This group represented subjects seen in a referral setting with a mean age of 66 years. Approximately $40 \%$ of the subjects were not followed for various reasons. During the course of 2.7 years, $41.3 \%$ of the subjects who were followed became demented for an annual conversion rate of approximately $15 \%$.

In a recent U.S. Class II study from Massachusetts General Hospital, persons were recruited from the community through media advertisements. ${ }^{17}$ A total of 123 persons with a Clinical Dementia Rating (CDR) of 0.5 (questionable dementia) were followed for 3 years. During this time frame, 23 individuals converted to probable AD for an annual rate of approximately $6 \%$.

In a U.S. Class III study from a large health maintenance organization in Seattle, a group of memory impaired subjects were followed. ${ }^{18}$ Of 811 subjects with a mean age of 74 years who had been recruited through a registry for cognitive complaints, 21 subjects with a severe isolated memory loss were followed for a mean of 48 months. During this time period, $48 \%$ developed dementia for an annual conversion rate of approximately $12 \%$ per year.

Investigators at New York University, in a Class III study using the Global Deterioration Scale as a measure to assess impairment, followed individuals with a Global Deterioration Scale rating of 3, which represented mild cognitive impairment for these investigators. ${ }^{19}$ They found that 16 of 32 of these individuals had progressed to a diagnosis of AD over 2.2 years $(25 \% \text { per year })^{19}$ and concluded that mild cognitive impairment was a risk factor for subsequent development of dementia.

Conclusions. Taken together, these studies indicate that individuals characterized as being cognitively impaired but not meeting clinical criteria for dementia or AD (mild cognitive impairment) have a high risk of progressing to dementia or $\mathrm{AD}$. If the figures for incident $\mathrm{AD}$ from the general population are used from table 4, one can see that the rates range 
Table 6 Cross-sectional data of instruments used in detection of dementia

\begin{tabular}{|c|c|c|c|c|c|c|}
\hline Authors & Instrument examined & $\begin{array}{c}\text { Patient population, } \\
\mathrm{n}\end{array}$ & $\begin{array}{l}\text { Sensitivity/ } \\
\text { specificity, } \\
\%\end{array}$ & $\begin{array}{c}\text { Positive } \\
\text { predictive value, } \\
\%\end{array}$ & $\begin{array}{c}\text { Negative } \\
\text { predictive value, } \\
\%\end{array}$ & $\begin{array}{l}\text { Class } \\
\text { of } \\
\text { eviden } \\
\text { ce }\end{array}$ \\
\hline \multicolumn{7}{|c|}{ Mini-Mental State Examination (MMSE) and general screening instruments } \\
\hline Ganguli et al. ${ }^{21}$ & $\begin{array}{l}\text { MMSE/population- } \\
\text { based }\end{array}$ & $1,367 />65$ y & $\begin{array}{l}49 / 92\left(10^{\text {th }}\right. \\
\text { percentil } \\
\text { e) }\end{array}$ & $\begin{array}{l}77\left(10^{\text {th }}\right. \\
\text { percentile })\end{array}$ & $\begin{array}{l}82\left(10^{\text {th }}\right. \\
\text { percentile })\end{array}$ & I \\
\hline Kukull et al. ${ }^{22}$ & $\begin{array}{l}\text { MMSE/standard } \\
\text { scores }\end{array}$ & 150/clinic-based & $63 / 96$ & 96 & 63 & I \\
\hline Wilder et al. ${ }^{24}$ & $\begin{array}{l}\text { MMSE/adjusted } \\
\text { scores }\end{array}$ & $795 />65 \mathrm{y}$ & $90 / 44$ & & & II \\
\hline
\end{tabular}

from $0.2 \%$ in the 65 to 69 age range to $3.9 \%$ in the 85 to 89 year range. The studies of mild cognitive impairment cited above indicate that the rate of progression to dementia or AD is between 6 and $25 \%$ per year.

\section{Practice recommendation.}

Patients with mild cognitive impairment should be recognized and monitored for cognitive and functional decline due to their increased risk for subsequent dementia. (Guideline).

Does screening at-risk subjects with a specific instrument in a specific setting accurately lead to the diagnosis of dementia? Because it is apparent that clinicians should be able to recognize persons in their practices with intermediate stages of cognitive impairment, it is helpful to survey which clinical instruments might be useful. Most of the studies on screening instruments compared dementia and control subjects rather than mild cognitive impairment subjects. The

\begin{tabular}{|c|c|c|c|c|c|c|}
\hline & & & & & & \\
\hline Tangalos et al. ${ }^{23}$ & $\begin{array}{l}\text { MMSE/age \& } \\
\text { education }\end{array}$ & $\begin{array}{l}3,515 / \text { community } \\
\text { population }\end{array}$ & 9 & $91(\mathrm{BR} 20)$ & $96(\mathrm{BR} 20)$ & II \\
\hline Fillenbaum et al. ${ }^{42}$ & $\begin{array}{l}\text { MMSE/subset } \\
\text { analysis }\end{array}$ & $\begin{array}{l}621 \mathrm{AD} / 412 \\
\text { controls }\end{array}$ & & & & III \\
\hline Mangi et al. ${ }^{43}$ & $\begin{array}{l}\text { MMSE/age \& } \\
\text { education }\end{array}$ & $\begin{array}{c}100 \mathrm{AD} / 749 \\
\text { controls }\end{array}$ & & & & III \\
\hline $\begin{array}{l}\text { Fountoulakis et } \\
\text { al. }^{25}\end{array}$ & $\begin{array}{l}\text { MMSE/standard } \\
\text { scores }\end{array}$ & 277 & & & & III \\
\hline Heun et al. ${ }^{44}$ & $\begin{array}{l}\text { MMSE/standard } \\
\text { scores }\end{array}$ & & $92 / 96$ & & & III \\
\hline Kokmen et al. ${ }^{26}$ & $\begin{array}{l}\text { Short Test of Mental } \\
\text { Status }\end{array}$ & $88 / 110$ demented & $86 / 88$ & & & III \\
\hline Solomon et al. ${ }^{28}$ & Seven-Minute Screen & $60 \mathrm{AD} / 60$ controls & $92 / 96$ & $54-95(\mathrm{BR} 5-50)$ & 99 (BR 5-50) & III \\
\hline Buschke et al. ${ }^{27}$ & $\begin{array}{l}\text { Memory Impairment } \\
\text { Score }\end{array}$ & $483 / 50$ demented & $87 / 96$ & $\begin{array}{l}\text { 54-85 for } \mathrm{AD} \\
\text { (BR 5-20) }\end{array}$ & & I \\
\hline \multicolumn{7}{|c|}{ Clock Drawing and Time Change Tests } \\
\hline Cahn et al. ${ }^{29}$ & Clock Drawing Test & $\begin{array}{l}\text { 199/possibly } \\
\text { cognitively } \\
\text { impaired/203 } \\
\text { controls }\end{array}$ & $83 / 72$ & & & I \\
\hline Bourke et al. ${ }^{45}$ & Clock Drawing Test & $\begin{array}{l}\text { 77/from Memory } \\
\text { Clinic }\end{array}$ & & & & III \\
\hline Lam et al. ${ }^{30}$ & Clock Drawing Test & $106 / 53$ demented & $83 / 79$ & 98 (BR 50) & & II \\
\hline Inouye et al. ${ }^{32}$ & $\begin{array}{l}\text { Time and Change } \\
\text { Test }\end{array}$ & $776 / 106$ demented & $86 / 71$ & 32 (BR 14) & 97 (BR 14) & II \\
\hline \multicolumn{7}{|c|}{ Neuropsychologic batteries } \\
\hline Wilder et al. ${ }^{46}$ & $\begin{array}{l}\text { Neuropsychologic } \\
\text { Battery }\end{array}$ & $795 />65 \mathrm{y}$ & $90 / 44-62$ & & & II \\
\hline Cahn et al. ${ }^{33}$ & $\begin{array}{l}\text { Neuropsychologic } \\
\text { Battery }\end{array}$ & $\begin{array}{l}\text { 199/possibly } \\
\text { cognitively } \\
\text { impaired/203 } \\
\text { controls }\end{array}$ & $82 / 98$ & & & II \\
\hline Swearer et al. ${ }^{34}$ & $\begin{array}{l}\text { Neuropsychologic } \\
\text { Battery }\end{array}$ & $87 / 53$ controls & $80 / 90$ & & & II \\
\hline Monsch et al. ${ }^{37}$ & Mattis Rating Scale & $359 / 254 \mathrm{AD}$ & $98 / 97$ & & & II \\
\hline Fisk et al. ${ }^{47}$ & $\begin{array}{l}\text { Halifax Mental } \\
\text { Status Scale }\end{array}$ & $361 / 16 \mathrm{AD}, 16 \mathrm{CI}$ & $88 / 86$ & & & III \\
\hline Loewenstein $^{36}$ & $\begin{array}{l}\text { Fuld Object Memory } \\
\text { Test }\end{array}$ & $\begin{array}{c}138 \mathrm{AD} / 53 \\
\text { controls }\end{array}$ & $95 / 98$ & & & III \\
\hline
\end{tabular}




\begin{tabular}{|c|c|c|c|c|c|c|}
\hline \multicolumn{7}{|c|}{ Informant-based instruments } \\
\hline Fuh et al. ${ }^{38}$ & IQCODE & 399/61 demented & $89 / 88$ & 45 (BR 10) & 99 (BR 10) & I \\
\hline Juva et al. ${ }^{41}$ & $\begin{array}{l}\text { Clinical Dementia } \\
\text { Rating (CDR) }\end{array}$ & 656 & $\begin{array}{l}92 / 94 \\
(\mathrm{CDR}>1)\end{array}$ & 73 (BR 14) & 99 (BR 14) & III \\
\hline Lam et al. ${ }^{39}$ & Blessed Roth Scale & $106 / 53$ demented & $91 / 98$ & & & II \\
\hline
\end{tabular}

$\mathrm{BR}=$ base rate; IQCODE = Informant Questionnaire on Cognitive Decline in the Elderly.

literature on which these recommendations are made is summarized in table 6 , according to the classification of instruments. A number of studies evaluated large groups of persons to determine whether screening instruments are useful for recognizing dementia at its earliest presentation. These studies provide useful information on the utility of screening instruments in the community or office practice setting. Most of these studies used the procedure of a screening technique and verified its utility with an independent standard for dementia. A summary of the sensitivities, specificities, and positive and negative predictive values for these instruments is outlined in table 6 .

General cognitive screening instruments. A widely recognized instrument for detection of cognitive impairment is the Mini-Mental State Examination (MMSE). ${ }^{20}$ Two U.S. Class I studies provide data on the MMSE. A random sample of 1367 community-dwelling individuals over the age of 65 years in a rural, low-education community sample were assessed using the MMSE (using a cutoff score at the 10th percentile of the population). The outcome of this study demonstrated that sensitivity was $49 \%$ with an acceptable specificity of $92 \%$ in detecting dementia with a CDR of 0.5 . ${ }^{21}$ The CDR is a 5 -point scale of severity with a CDR 0 representing normal subjects, CDR $\geq 0.5$ questionable dementia, and CDR 1,2 , and 3 pertaining to mild, moderate, and severe dementia, respectively. In another study, the MMSE was also evaluated in a registry setting in which 150 consecutive patients with cognitive complaints were administered the examination, and the results were compared with a 1 -year follow-up diagnosis. ${ }^{22}$ These data indicated the standard cutoff score of $<24$ on the MMSE was insensitive (63\%), whereas the specificity was good (96\%).

There were two U.S. Class II studies that concerned screening general populations with the MMSE. In a large study of the MMSE from the Mayo Clinic, 3513 elderly subjects were administered the MMSE and followed longitudinally. ${ }^{23}$ The investigators concluded that a decline of 4 or more points in the MMSE over 1 to 4 years indicated a significant cognitive change. When the cutoff scores were adjusted for age and educational levels, the sensitivity improved (82\%) while maintaining excellent specificity (99\%). When administered to a population with a high prevalence of dementia (20\%), the positive predictive value (PPV) was $91 \%$ with a negative predictive value (NPV) of $96 \%$. When used in a population with a lower base rate of dementia (5\%), the PPV fell to $68 \%$ with an NPV of $99 \%$. The MMSE, originally designed as a bedside screening tool for the clinician, therefore appears to have limitations as a screening tool in general population assessments; however, it appeared to be quite useful in examining patients at increased risk for dementia (e.g., Mild Cognitive Impairment), particularly when age and education adjustments were implemented.

In another U.S. population-based study of patients over the age of 65 in North Manhattan, the MMSE was found to have low specificity (44\%) when the cutoff point was adjusted to ensure a sensitivity of $90 \%{ }^{24}$ This study demonstrated the limitations of using the MMSE in isolation when discriminating between demented and nondemented patients in a general population.

In a Class III study from Greece as a part of the World Health Organization Program for Research on Aging and Age-Associated Dementias, the MMSE was compared with the Diagnostic and Statistical Manual (DSM) IV criteria for dementia and the National Institute of Neurologic, Communicative Disorders and Stroke-AD and Related Disorders Association criteria for AD. ${ }^{25}$ In a sample of 277 subjects with widely varying education from the general population, the MMSE had low specificity (57\%) with high sensitivity (100\%).

Performance on the Kokmen Short Test of Mental Status was assessed in a sample of 288 consecutive subjects suspected of cognitive impairment referred to a memory clinic. ${ }^{26}$ The possibility of dementia was considered when an MMSE score was $<24$ or when a family member or physician suspected a memory impairment. Sensitivity of $86 \%$ and specificity of $88 \%$ were achieved for detecting dementia as defined by DSM III-R criteria.

In another U.S. Class I study, investigators at Albert Einstein College of Medicine used the Memory Impairment Screen for dementia. ${ }^{27}$ This screen consisted of a four-item delayed and cued recall test. The investigators studied a sample of 483 elderly individuals, 50 with an independent diagnosis of dementia using the DSM III-R criteria. The memory screening tool demonstrated good sensitivity $(87 \%)$, specificity $(96 \%)$, and PPV (85\%) when the prevalence of disease was $20 \%$, with a low PPV (54\%) when the base rate of disease was $5 \%$.

In another U.S. Class III study a 7-minute screening instrument comprising enhanced cued recall, category fluency, Benton Temporal Orientation Test, and Clock Drawing Test (CDT) was administered to 60 consecutive patients with AD sent to a memory disorders clinic as well as 60 age-matched controls recruited from newspaper ads and by an HMO. ${ }^{28}$ The sensitivity of this examination was $92 \%$ with a specificity of $96 \%$.

Conclusion. General cognitive screening instruments, which include the MMSE, Kokmen Short Test of Mental Status, 7-Minute Screen, and Memory Impairment Screen, are useful for the detection of dementia when used in patient populations with an elevated prevalence of cognitive impairment either due to age or presence of memory dysfunction. 


\section{Practice recommendation.}

General cognitive screening instruments (e.g., MMSE) should be considered for the detection of dementia in individuals with suspected cognitive impairment (Guideline).

Brief focused screening instruments. A tool which has experienced popularity in assessing patients for cognitive impairment is the CDT. Scores are based on the patient's ability to properly draw the face of a clock by appropriate placement of the numbers and the hands of the clock to a designated time. In the Class II Rancho Bernardo populationbased study, 199 patients over the age of 65 were designated as having possible cognitive impairment after undergoing an initial screen. ${ }^{29}$ They were administered the CDT as were 203 age-matched normal elderly (screen negative) from the same population base. The cutoff scores were determined (using ROC curves) and resulted in sensitivity of $83 \%$ and specificity of $72 \%$ for the global scores.

In another Class II study, 106 elderly Chinese patients were administered the CDT as well as the tasks of reading the time from a set clock and setting a clock to a designated time. ${ }^{30}$ When using the designated cutoff points and determining the presence of dementia using the DSM III-R criteria, the CDT demonstrated a moderate sensitivity of $83 \%$ and specificity of $79 \%$.

The Time and Change Test, which is an instrument assessing the subject's ability to tell time and make change, was evaluated in a Class I ${ }^{31}$ and a Class II $^{32}$ study. In the Class I study, 100 consecutive patients 70 years of age or older were assessed using this task, and the results were compared with a standard diagnosis based on the Blessed Dementia Rating Scale (BDRS) and the MMSE. The sensitivity in this sample was $94 \%$ with a specificity of $46 \%$. These results are limited by use of the BDRS and the MMSE as reference standards for dementia. The authors argue that these instruments have the potential to reduce unrecognized cases of dementia but should not be used in isolation when making the determination of a dementing illness. The Class II study was performed on 776 consecutive inpatients greater than 65 years of age. The instrument demonstrated a moderate specificity $(71 \%)$ and sensitivity $(86 \%)$ with a poor PPV $(34 \%)$ and excellent NPV $(97 \%)$ when the base rate of disease was $14 \%$.

Conclusion. Recently attempts have been made to develop useful screening tools that can be administered in a brief time frame. Caution must be exercised because of the limited scope of these tools.

\section{Practice recommendation.}

Brief cognitive assessment instruments that focus on limited aspects of cognitive function (i.e., CDT, Time and Change Test) may be considered when screening patients for dementia (Option).

Neuropsychologic batteries. The utility of neuropsychologic batteries in evaluating patients with possible dementia has been addressed in several Class II studies. The Ranchø Bernardo population was examined using tests of verbal and nonverbal memory, mental flexibility, and confrontational naming. ${ }^{33}$ A logistic model was derived and correctly classified $82 \%$ of the subjects with AD and $98 \%$ of the normal elderly subjects. When a cross-validation study was performed on an independent sample of 46 subjects (27 normal controls and 19 patients with AD) from a clinic, the sensitivity improved to $89 \%$ with the specificity remaining high at $100 \%$. This suggests that psychometric discrimination of AD may be less accurate in a community-dwelling population than in clinic-based samples.

In the North Manhattan Aging Project, 795 patients over the age of 65 were administered a battery of tests and a "culture-fair" neuropsychologic examination. ${ }^{24}$ When the sensitivity was set to $90 \%$ (by using ROC curves) the tests all demonstrated rather poor specificity for detecting dementia (results ranging from 44 to $62 \%$ ).

Another Class II U.S. study was conducted on 87 patients referred to the University of Massachusetts Memory Clinic who were found to have verbal IQ $>110 .{ }^{34}$ These examinations identified $80 \%$ of the demented and $96 \%$ of the nondemented subjects correctly. Recall of prose passages was found to be one of the best discriminators of mild dementia versus normal cognition in this elderly sample.

In a Class III study from Italy, a neuropsychologic battery examining activities of daily living, affect, verbal and spatial memory, orientation, calculation, language, writing and reading comprehension, and visuomotor function was tested in 143 subjects with $\mathrm{AD}$ and 146 hospitalized age- and education-matched controls. ${ }^{35}$ These tests, when analyzed using a logistic model, demonstrated a sensitivity of $87 \%$ with a specificity of $90 \%$ when detecting demented versus nondemented subjects.

Several Class III studies examined various instruments used in the detection of dementia. An object memory test was used on both English- and Spanish-speaking patients recruited from a memory clinic. ${ }^{36}$ When a cutoff score of 29 points was implemented the test had a specificity of $98 \%$ and a sensitivity of $96 \%$. The applicability of these findings to the general elderly population is uncertain.

The Mattis Dementia Rating Scale was assessed in a Class II study in 254 patients with AD and 105 elderly controls. ${ }^{37}$ This scale tests the areas of attention, initiation/perseveration, construction, memory, and conceptualization. When a cutoff score of $129 / 144$ points was used the sensitivity was $98 \%$ and the specificity was $97 \%$. When the rating 
scale was applied to a community-based sample the test correctly identified $91 \%$ of the patients with AD and $93 \%$ of the normal elderly subjects.

Conclusion. Neuropsychologic batteries are useful instruments in identifying patients with dementia, particularly when administered to an increased-risk (by virtue of memory impairment) population. Those neuropsychologic instruments that emphasize memory function are most useful.

\section{Practice recommendation.}

Neuropsychologic batteries should be considered useful in identifying patients with dementia, particularly when administered to a population at increased risk of cognitive impairment (Guideline).

Informant-based instruments. There are a variety of other screening instruments that have been evaluated for their usefulness in identifying patients with dementia. Some of these emphasize history from an informant. In a Class I study, an informant-based technique, the Informant Questionnaire on Cognitive Decline in the Elderly (IQCODE), was used in an illiterate Chinese population consisting of 399 community residents and 61 patients with dementia. ${ }^{38}$ Performance on the informant-based instrument was compared with an independent diagnosis of dementia by physicians using the DSM III-R criteria. The IQCODE performed well with a sensitivity of $89 \%$ and a specificity of $88 \%$. Its performance was better than a derived MMSE score in a population with a large variation in educational background. The authors caution that the examination assumes that the informants are objective and honest with their ratings, and variations from this will significantly alter the results.

The BDRS, a 22-question informant-based instrument, was assessed in 53 demented and 53 age-matched controls in a Class II study. ${ }^{39}$ The patients were obtained from social centers, retirement homes, and outpatient clinics in Hong Kong. The instrument demonstrated a specificity of $98 \%$ and a sensitivity of $91 \%$; however interrater reliability for the individual items on the instrument was poor.

The CDR scale is a 6-category, informant-based examination dealing with orientation, judgment, memory, community affairs, personal care, and home and hobbies. ${ }^{40}$ In a study of a random sample of 656 Helsinki residents older than 75 years, 174 were found to have a CDR score $>0.5 .^{41}$ These patients were examined by a neurologist using the DSM III-R criteria for defining dementia. When a cutoff score of CDR $\geq 1$ was used, this instrument demonstrated a specificity of $94 \%$ with a sensitivity of $92 \%$.

Conclusion. Interview-based techniques (i.e., BDRS, CDR, IQCODE) may be useful in identifying patients with dementia, particularly when administered to patients who are at inereased risk of developing dementia by virtue of age or memory impairment. These instruments emphasize the importance of obtaining information concerning the cognitive and functional status of persons from an informed source.

\section{Practice recommendation.}

Interview-based techniques may be considered in identifying patients with dementia, particularly in a population at increased risk for cognitive impairment(Option)

Recommendations for future research. Although the data summarized in this document are very useful in addressing the issue of the early screening or detection of dementia in normal or mildly impaired subjects, many questions are raised by this review. We need a better understanding of cognitive function in normal aging. All these recommendations are predicated upon the notion that these subjects have declined from a previous level of function and that this decline exceeds what one expects for normal aging. However, the definitive course of cognitive function in normal aging has not been determined. In addition, variables other than cognitive function should also be assessed for their potential predictive validity. For example, perhaps demographic variables such as age, education, family history of dementia, and genetic susceptibility, disorders affecting mental status such as depression and morphologic features of the brain, or functional brain imaging may also be helpful in determining an ultimate decline.

Additional studies are needed to allow the clinician to differentiate among the screening instruments assessed in the various studies described above. In particular, there are few studies that address the direct comparison of instruments, e.g., the MMSE versus CDT. These issues become relevant in a time-constrained practice. In addition, it would be useful to know the utility of subjective memory questionnaires, activities of daily living screening instruments, and other noncognitively oriented instruments.

The studies discussed in this review are important only insofar as the ultimate detection of dementia proves to be beneficial. That is, if early cognitive decline can be arrested or reversed by therapeutic intervention, the value of these studies becomes apparent. In addition, the utility of counseling, assistance with decision making, driving, and legal, financial, and long-term care planning are all relevant issues. Because parallel work on the basic biology of dementing illnesses is progressing rapidly, it is incumbent upon clinical investigators to characterize these populations. When appropriate therapeutic interventions become available, clinical investigators will already have multiple, well characterized sets of subjects that would be amenable to treatment with these therapies. 
The ultimate economic impact of this work is also significant. Because the segment of the population that is achieving the seventh and eighth decades of life is increasing at a rapid pace, the societal impact of dementing illnesses, which are strongly age-related, is large. There are additional considerations concerning quality of life, caregiver burden, health service utilization, institutionalization, and mortality that must be addressed.

Disclaimer. This statement is provided as an educational service of the American Academy of Neurology. It is based on an assessment of current scientific and clinical information. It is not intended to include all possible proper methods of care for a particular neurologic problem or all legitimate criteria for choosing to use specific procedures. Neither is it intended to exclude any reasonable alternative methodologies. The AAN recognizes that specific patient care decisions are the prerogative of the patient and the physician caring for the patient, based on all the circumstances involved.

\section{Acknowledgment}

The authors thank Wendy Edlund, Alison Nakashima, and James Stevens, MD, at the AAN for their superb assistance in coordinating this project; Vicki Glasgow of the University of Minnesota Biomedical Library for performing the literature searches; and Donna Asleson and Jackie Evans for preparing the manuscript.

\section{Appendix}

Quality Standards Subcommittee Members: Gary Franklin, MD, MPH, Co-Chair; Catherine Zahn, MD, Co-Chair; Milton Alter, MD, $\mathrm{PhD}$; Stephen Ashwal, MD; John Calverley, MD; Richard M. Dubinsky, MD; Jacqueline French, MD; Michael Glantz, MD; Gary Gronseth, MD; Deborah Hirtz, MD; Robert G. Miller, MD; James Stevens, MD, Facilitator; and William J. Weiner, MD.

\section{References}

1. Practice parameter for diagnosis and evaluation of dementia. (summary statement). Report of the Quality Standards Subcommittee of the American Academy of Neurology. Neurology 1994; 44: 2203-2206.

2. Petersen RC, Smith GE, Waring SC, et al. Mild cognitive impairment: clinical characterization and outcome. Arch Neurol 1999; 56: 303-308.

3. Brookmeyer R, Gray S, Kawas C. Projections of Alzheimer's disease in the United States and the public health impact of delaying disease onset. Am J of Pub Health 1998; 88: 1337-1342.

4. Katzman R, Fox PJ. The world-wide impact of dementia: projections of prevalence and costs. In: Mayeux R, Christen Y, eds. Epidemiology of Alzheimer's disease: from gene to prevention. Heidelberg: Springer-Verlag, 1999: 1-17.

5. Hy LX, Keller DM. Prevalence of AD among whites: a summary by levels of severity. Neurology 2000; 55: 198-204.

6. Albert MS, Drachman DA. Alzheimer's disease: what is it, how many people have it, and why do we need to know? Neurology 2000; 55: 166-168.

7. Hebert LE, Scherr PA, Beckett LA, et al. Age-specific incidence of Alzheimer's disease in a community population. JAMA 1995; 273: 1354-1359.

8. Bachman DL, Wolf PA, Linn RT, et al. Incidence of dementia and probable Alzheimer's disease in a general population. The Framingham Study. Neurology 1993; 43.515-519.

9. Gao S, Hendrie HC, Hall KS, et al. The relationships between age, sex, and the incidence of dementia and Alzheimer's disease. A meta-analysis. Arch Gen Psychiatry 1998; 55: 809-815.

10. Petersen RC. Mild cognitive impairment. Transition from aging to Alzheimer's disease. In: Iqbal K, Sisodia SS, Winblad B, eds. Alzheimer's disease: advances in etiology pathogenesis and therapeutics. West Sussex, England: John Wiley \& Sons (in press).

11. Crook T, Bartus RT, Ferris SH, et al. Age-associated memory impairment: proposed diagnostic criteria and measures of clinical change: report of a National Institute of Mental Health work group. Dev Neuropsychol 1986; 2: 261-276.

12. Levy R. Age-associated cognitive decline. Int Psychoger 1994; 6: 63-68.

13. Smith GE, Ivnik RJ, Petersen RC, et al. Age-associated memory impairment diagnoses: problems of reliability and concerns for terminology. Psychol Aging 1991; 6: 551-558.

14. Tierney MC, Szalai JP, Snow WG, et al. Prediction of probable Alzheimer's disease in memory-impaired patients: a prospective longitudinal study. Neurology 1996; 46: 661-665.

15. Tierney MC, Szalai JP, Snow WG, et al. A prospective study of the clinical utility of ApoE genotype in the prediction of outcome in patients with memory impairment. Neurology 1996; 46: 149-154.

16. Devanand DP, Folz M, Gorlyn M, et al. Questionable dementia: clinical course and predictors of outcome. JAGS 1997; 45: 321328.

17. Daly E, Zaitchik D, Copeland M, et al. Predicting conversion to Alzheimer's disease using standardized clinical information. Arch Neurol 2000; 57: 675-680.

18. Bowen J, Teri L, Kukull W, et al. Progression to dementia in patients with isolated memory loss. Lancet 1997; 349: 763-765.

19. Flicker C, Ferris SH, Reisberg B. Mild cognitive impairment in the elderly: predictors of dementia. Neurology 1991; 41: 10061009.

20. Folstein MF, Folstein SE, McHugh PR. Mini-Mental State. A practical method for grading the cognitive state of patients for the clinician. J Psychiatr Res 1975; 12: 189-198.

21. Ganguli M, Belle S, Ratcliff G, et al. Sensitivity and specificity for dementia of population-based criteria for cognitive impairment: The Movies Project. J Gerontol 1993; 48: M152-M161.

22. Kukull WA, Larson EB, Teri L, et al. The Mini-Mental State Examination score and the clinical diagnosis of dementia. J Clin Epidemiol 1994; 47: 1061-1067.

23. Tangalos EG, Smith GE, Ivnik RJ, et al. The Mini-Mental State Examination in general medical practice: clinical utility and acceptance. Mayo Clin Proc 1996; 71: 829-837. 
24. Wilder D, Cross P, Chen MPJ. Operating characteristics of brief screens for dementia in a multicultural population. Am J Geriatr Psychiatry 1995; 3: 96-107.

25. Fountoulakis KN, Tsolaki M, Mohs RC, et al. Epidemiological Dementia Index: a screening instrument for Alzheimer's disease and other types of dementia suitable for use in populations with low education level. Dement Geriatr Cogn Disord 1998; 9: 329338.

26. Kokmen E, Smith GE, Petersen RC, et al. The short test of mental status: correlations with standardized psychometric testing. Arch Neurol 1991; 48: 725-728.

27. Buschke H, Kulansky G, Katz M, et al. Screening for dementia with the Memory Impairment Screen. Neurology 1999; 52: 231238.

28. Solomon PR, Hirschoff A, Kelly B, et al. A 7-minute neurocognitive screening battery highly sensitive to Alzheimer's disease. Arch Neurol 1998; 55: 349-355.

29. Cahn D, Salmon D, Monsch A. Screening for dementia of the Alzheimer type in the community: the utility of the Clock Drawing Test. Arch Clin Neuropsychol 1996; 11: 529-539.

30. Lam L, Chiu H, Ng K, et al. Clock-face drawing, reading and setting tests in the screening of dementia in Chinese elderly adults. J Gerontol 1998; 538: 353-357.

31. Froehlich TE, Robison JT, Inouye SK. Screening for dementia in the outpatient setting: the Time and Change Test. J Am Geriatr Soc 1998; 46: 1506-1511.

32. Inouye SK, Robison JT, Froehlich TE, et al. The Time and Change Test: a simple screening test for dementia. J Gerontol 1998; 53A: M281-M286.

33. Cahn DA, Salmon DP, Butters N, et al. Detection of dementia of the Alzheimer type in a population-based sample: neuropsychological test performance. J Int Neuropsychol Soc 1995; 1: 252-260.

34. Swearer JM, O'Donnell BF, Kane KJ, et al. Delayed recall in dementia: sensitivity and specificity in patients with higher than average intellectual abilities. Neuropsychiatry Neuropsychol Behav Neurol 1998; 11: 200-206.

35. Bracco L, Amaducci L, Pedone D, et al. Italian multi-center study on dementia (SMID: a neuropsychological test battery for assessing Alzheimer's disease). J Psychiatr Res 1990; 24: 213-226.

36. Loewenstein DA, Duara R, Arguelles T, et al. Use of the Fuld Object-Memory Evaluation in the detection of mild dementia among Spanish and English-speaking groups. Am J Geriatr Psych 1995; 3: 300-307.

37. Monsch AU, Bondi MW, Salmon DP, et al. Clinical validity of the Mattis Dementia Rating Scale in detecting dementia of the Alzheimer type: a double cross-validation and application to a community-dwelling sample. Arch Neurol 1995; 52: 899-904.

38. Fuh JL, Teng EL, Lin KN, et al. The informant questionnaire on cognitive decline in the elderly (IQCODE) as a screening tool for a predominantly illiterate Chinese population. Neurology 1995; 45:92-95.

39. Lam LCW, Chiu HFK, Li SW, et al. Screening for dementia: a preliminary study on the validity of the Chinese version of the Blessed-Roth Dementia Scale. Int Psychogeriatr 1997; 9: 39-46.

40. Morris JC. The Clinical Dementia Rating (CDR): current version and scoring rules. Neurology 1993; 43: $2412-2414$.

41. Juva K, Sulkava R, Erkinjuntti T, et al. Usefulness of the Clinical Dementia Rating scale in screening for dementia. Int Psychogeriatr 1995; 7: 17-24.

42. Fillenbaum GG, Wilkinson WE, Welsh KA, et al. Discrimination between stages of Alzheimer's disease with subsets of MiniMental State Examination items. Arch Neurol 1994; 51: 916-921.

43. Magni E, Binetti G, Cappa S, et al. Effect of age and education on performance on the Mini-Mental State Examination in a healthy older population and during the course of Alzheimer's disease. J Am Geriatr Soc 1995; 43: 942-943.

44. Heun R, Papassofirotoulos A, Jennssen F. The validity of psychometric instruments for detection of dementia in the elderly general population. Int J Geriatr Psychiatry 1998; 13: 368-380.

45. Bourke J, Castleden CM, Stephen R, et al. A comparison of clock and pentagon drawing in Alzheimer's disease. Int J Geriatr Psychiatry 1995; 10: 703-705.

46. Wilder D, Cross P, Chen J, et al. Operating characteristics of brief screens for dementia in a multicultural population. Am J Geriatr Psychiatry 1995; 3: 96-107.

47. Fisk JD, Rockwood K, Hondas B, et al. Cognitive screening in a population-based sample of community-living elderly: effects of age and education on the construct of cognitive status. Int J Geriatr Psychiatry 1995; 10: 687-694. 


\section{Neurology}

Practice parameter: Early detection of dementia: Mild cognitive impairment (an evidence-based review) [RETIRED]: Report of the Quality Standards Subcommittee of the American Academy of Neurology

R. C. Petersen, J.C. Stevens, M. Ganguli, et al.

Neurology 2001;56;1133-1142

DOI 10.1212/WNL.56.9.1133

This information is current as of May 8, 2001

Updated Information \&

Services

Citations

Permissions \& Licensing

Reprints including high resolution figures, can be found at: http://n.neurology.org/content/56/9/1133.full

This article has been cited by 84 HighWire-hosted articles: http://n.neurology.org/content/56/9/1133.full\#\#otherarticles

Information about reproducing this article in parts (figures,tables) or in its entirety can be found online at:

http://www.neurology.org/about/about_the_journal\#permissions

Information about ordering reprints can be found online:

http://n.neurology.org/subscribers/advertise

Neurology ${ }^{\circledR}$ is the official journal of the American Academy of Neurology. Published continuously since 1951, it is now a weekly with 48 issues per year. Copyright. All rights reserved. Print ISSN: 0028-3878. Online ISSN: 1526-632X.

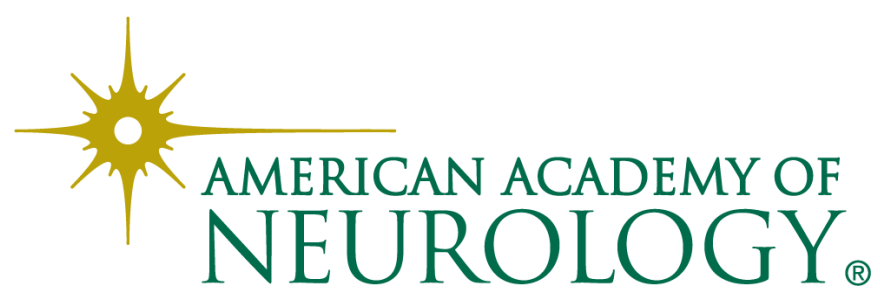

